\title{
Program Humas Dalam Membangun Citra Perusahaan di PT Hajjatan Media Solusindo
}

\author{
Muhammad Iqbal $^{1}$, Dedy Zebua ${ }^{2}$, Berliana Lukitawati ${ }^{3}$ \\ ${ }^{1,2,3}$ Sekolah Tinggi Ilmu Komunikasi Indonesia Maju \\ Email correspondent: iqbalkibbo97@gmail.com
}

\begin{abstract}
Abstrak
Hajjatan.com adalah perusahaan online market place merupakan sebuah perusahaan jasa atau sebagai market place/tempat bertemu yang punya hajjat dan vendor penyedia jasa/barang hajatan secara online di seluruh indonesia. Berbeda dengan lainnya Perusahaan ini hadir sebagai solusi mudah hajjatan dan membawa solusi dan kemudahan yang di sebut sebagai one stop service untuk segala kebutuhan hajjatan. kami hadir menjadi bagian dari solusi segala hajjatan anda. Dalam membangun sebuah perusahaan tugas public relations adalah menyelenggarakan publikasi atau menyebarluaskan informasi Kegiatan Merancang sebuah kegiatan yang bertujuan memperkenalkan produk dan layanan perusahaan, mendekatkan diri ke publik dan lebih jauh lagi dapat mempengaruhi opini publik Agar mendapatkan citra baik. Sifat penelitian ini adalah kualitatif, dengan studi deskriptif. Jenis dan tehnik pengumpulan data primer yang diproleh dari wawancara. Sementara data sekunder diproleh dari data yang berbentuk buku,web, artikel, hasil penelitian. Dalam membangun sebuah citra perushaan peneliti menggunakan konsep stategi humas "PENCILS" untuk meneliti cara dalam membangun sebuah citra dalam sebuah perusahaan
\end{abstract}

Kata kunci: program humas, citra perusahaan

\begin{abstract}
Hajjatan.com is an online market place company which is a service company or as a market place / place to meet those who have celebrations and vendors who provide services / goods for celebration online throughout Indonesia. Unlike the others, this company exists as an easy solution for celebrations and brings a solution and convenience that is called a one stop service for all celebration needs. we are here to be part of the solution for all your celebration. In building a company, the task of public relations is to organize publications or disseminate information. Activity Designing an activity that aims to introduce the company's products and services, get closer to the public and further influence public opinion in order to get a good image. The nature of this research is qualitative, with a descriptive study. Types and techniques of primary data collection obtained from interviews. Meanwhile, secondary data is obtained from data in the form of books, web, articles, and research results. In building a company image, researchers use the concept of the PR strategy "PENCILS" to examine ways to build an image within a company.
\end{abstract}

Keywords: public relations program, company image. 


\section{Pendahuluan}

Perkembangan di dunia teknologi dan Keberhasilan seseorang dalam dunia bisnis ditentukan seberapa baik mereka melakukan komunikasi, Kegiatan komunikasi yang dilakukan dapat menggunakan berbagai media komunikasi yang ada, baik media komunikasi nonelektronik/ konvensional maupun media komunikasi elektronik. Media komunikasi nonelektronik antara lain adalah penggunaan bahasa lisan, bahasa isyarat/ bahasa tubuh, dan aneka media komunikasi yang menggunakan kertas (aneka macam surat menyurat, surat kabar, majalah dan tabloid). Sedangkan media komunikasi elektronik antara lain adalah media audio-visual (televisi), intercom, radio panggil (pager), internet (situs web dan e-mail [electronic mail]), teleconference, video conference, telepon biasa (fixed line), dan telepon genggam/ seluler (handphone). ${ }^{1}$

Melalui sarana - sarana yang ada dalam internet kita dapat memperoleh informasi dengan mudah, praktis dan cepat sehingga tidak membuang waktu. Peranan teknologi informasi dalam bidang komunikasi sangatlah besar, karena dalam adanya informasi yang mendukung, akan terciptalah komunikasi yang efektif, dan dengan adanya kemajuan dari kedua bidang tersebut para pelaku bisnis rela membayar mahal biaya publikasi/reklame untuk satu jenis produk. Perkembangan-perkembangan yang terjadi dapat di katakan seiring dengan di temukan inovasi teknologi tertentu di mulai dari bahasa (lisan dan tulisan), alat cetak hingga telegraf.

Dalam dunia bisnis dengan skala kecil, menegah, maupun besar, orang-orang yang terlibat di dalamnya (para pelaku bisnis) tidak dapat lepas dari kegiatan komunikasi. Oleh karena itu bagi mereka komunikasi merupakan faktor yang sangat vital dan penting kedudukannya demi pencapaian tujuan. Mereka dapat menggunakan berbagai media komunikasi yang ada, baik yang konvensional maupun yang elektronik sebagai penyampaian pesan-pesan bisnis dan Abad informasi disebut juga dengan abad ruang angkasa elektronika, desa dunia. masyarakat yang hidup pada abad informasi yang kemudian di sebut masyrakat informasi (information society), di tandai dengan makin meningkatnya pekerja-pekerja di bidang informasi. pada puncak masyrakat industrial, menunjukan bahwa proposi pekerjaan yang bergerak di bidang informasi meningkat $30 \%$ yang sebelumnya hanya $10 \%$

Pada saat ini (tahun 2000-an), proporsi pekerja di bidang informasi hanya di bawah 50\% meskipun angka ini tidak termasuk pertumbuhan jumlah pegawai pabrik, pedagang eceran, dan pertanian yang membelanjakan banyak dari keseharian mereka di terminal terminal computer yang mungkin dapat di klasifikasikan sebagai pekerja-pekerja informasi (kasus amerika) sehubungan media merupakan refleksi status ekonomi masyrakat, tidak mengherankan apabila domisili media dalam masyrakat informasi adalah satu hal untuk membantu mereka menciptakan, menyimpan dan memperoses informasi.

Pendayagunaan teknologi internet dalam komunikasi massa saat ini telah membawa banyak perubahan pada fungsi dan sistem media massa konvensional. Teknologi internet yang mengandalkan sistem jaringan tidak terpusat telah memungkinkan semua orang dengan secara interaktif, mencari, mendapat, menyimpan, memproses, membuat dan mempublikasi informasi. Internet seolah telah menjadi kekuatan media massa modern, dimana kebebasan, interaktivitas, fleksibilitas dan desentralisasi menjadi pilar-pilar utamanya.Jika pada awalnya internet hanya digunakan untuk memudahkan riset, pemograman, surat dan informasi secara elektronik dikalangan para pendidik.

Perkembangan sistem informasi dan teknologi mempercepat proses globalisasi, proses komunikasi terjadi setiap saat tanpa berhenti dan berlangsung pada saat yang hampir bersamaan di seluruh belahan dunia. Informasi dengan mudah dan cepat menyebar. Perkembangan sistem informasi dan teknologi mempercepat proses globalisasi, sehingga proses komunikasi terjadi setiap saat tanpa berhenti dan berlangsung pada saat yang hampir bersamaan di seluruh belahan dunia. Informasi dengan mudah dan cepat menyebar, bahkan nyaris tanpa penghalang apapun. Dari pengamatan tersebut memungkinkan orang untuk berkomunikasi melalui berbagai macam media dan memungkinkan 
komunikasi berkembang menjadi suatu bisnis tersendiri. Tantangan ke depan, bukan saja sekedar menjual produk \& jasa perusahaan, tetapi bagaimana menyampaikan pesan bahwa produk atau jasa yang ditawarkan dapat memberikan manfaat kepada banyak orang dari berbagai ragam budaya, latar belakang, dan sebagainya. Proses penyampaian pesan atau informasi tersebut, dapat dilakukan secara satu arah, seperti melalui media elektronik atau media cetak juga dapat dilakukan secara dua arah (interaktif) melalui jaringan internet. ${ }^{2}$

Teknologi informasi saat ini, telah menciptakan jenis-jenis dan peluang-peluang bisnis yang baru di mana transaksi-transaksi bisnis makin banyak dilakukan secara elektronika. Dengan perkembangan teknologi informasi tersebut memungkinkan setiap orang dengan mudah melakukan perbuatan hukum seperti misalnya melakukan jual-beli. internet memang cepat dan memberi pengaruh signifikan dalam segala aspek kehidupan kita beberapa tahun terakhir ini dengan begitu merebaknya internet menyebabkan banyaknya perusahaan yang mulai mencoba menggunakan media ini. Dan salah satu manfaat dari keberadaan internet adalah sebagai media promosi. keuntungan besar bagi pengusaha yang produknya di kenal di seluruh dunia. sarana untuk melakukan transaksi perdagangan yang sekarang di Indonesia telah mulai penggunaan nya oleh beberapa perusahaan yaitu electronic commerce atau yang lebih dikenal dengan E-Commerce, yang merupakan bentuk perdagangan secara elektronik melalui media internet. E-Commerce pada dasarnya merupakan suatu kontak transaksi perdagangan antara penjual dan pembeli dengan menggunakan media internet. Jadi proses pemesanan barang di komuni kasikan melalui internet. "Yuan Gao (2005), Encyclopedia of Information Science and Technology menyatakan E-Commerce adalah penggunaan jaringan komputer untuk melakukan komunikasi bisnis dan transksaksi komersial. diwebsite E-CommerceNet, sebagai kegiatan menjual barang dagangan dan/atau jasa melalui internet. Seluruh komponen yang terlibat dalam bisnis praktis diaplikasikan disini yang dijual, cara online. ${ }^{3}$

Salah satu bidang bisnis yang sekarang marak di kalangan masyarakat adalah bisnis di bidang hajatan hal ini dikarenakan pernikahan sudah menjadi rutinitas sehari-hari dalam masyrakat dan merupakan moment yang sangat penting untuk di rayakan bersama keluarga besar dan teman-teman, setiap orang yang akan melangsungkan acara pastinya membutuhkan persiapan untuk pernikahannya seperti wedding organizer, catrering, make-up, tenda, dekorasi dll. Pernikahan merupakan acara sakral yang terjadi seumur hidup dan juga sudah sudah menjadi gaya hidup masyrakat di setiap acara pernikahan. 14

Namun di indonesia hajatan itu bukan sekedar mengadakan pesta pernikahaan saja tapi bagi orang indonesia hajatan itu adalah katalain dari tuan rumah yang mengadakan pesta/siapa yang punya hajat, hajatan merupakan acara seperti pernikahan, khitanan, arisan, akikah atau acara adat lainnya, sepertinya hal tersebut tidak akan pernah lepas dari indonesia, karna indonesia memiliki berbagai macam budaya dan adat istiadat dan banyak pula tradasi yang harus di lakukan tergantung kebudayaan yang di warisi oleh keluarga, terkadang kesulitan mencari setiap kebutuhan acara hajatan, baik berupa makanan, tempat, perlengkapan dan faktor penunjang lainnya, yang dapat dipercaya, mudah, murah dan efisien .

Hajjatan.com adalah perusahaan online market place merupakan sebuah perusahaan jasa atau sebagai market place/tempat bertemu yang punya hajjat dan vendor penyedia jasa/barang hajatan secara online di seluruh indonesia. Berbeda dengan lainnya Perusahaan ini hadir sebagai solusi mudah hajjatan dan membawa solusi dan kemudahan yang di sebut sebagai one stop service untuk segala kebutuhan hajjatan. kami hadir menjadi bagian dari solusi segala hajjatan anda, bukan hanya pernikahan/wedding saja syukuran, arisan, pentas seni, wisuda, meeting/pertemuan, aqiqah, sunatan, ulangtahun, ucapan selamat dll

Dengan kesibukan masyarakat yang sangat tinggi, dan juga kemajuan teknologi yang pesat, masyarakat Indonesia ingin segala sesuatu ataupun urusannya ingin serba cepat, mudah, efisien , 
terpercaya dan terpusat, untuk itu hajjatan.com hadir sebagai solusi dan menjawab segala kebutuhan hajatan masyarakat indonesia. dalam Membangun sebuah perusahaan industry kreatif tentunya tidak terlepas oleh seorang Public relations dan strateginya atau aspek - aspek pendekatan humas dalam menjalankan tanggung jawab dan fungsinya untuk menciptakan iklim yang kondusif antara perusahaan dengan publiknya dalam membangun citra positif perusahaan maupun organisasi harus dibangun melalui beberapa cara/strategi yang matang agar kegiatan yang dijalankan dapat berjalan secara lancar. ${ }^{3}$

Setiap fungsi dan tugas public relations adalah menyelenggarakan publikasi atau menyebarluaskan informasi Kegiatan Merancang sebuah kegiatan yang bertujuan memperkenalkan produk dan layanan perusahaan, mendekatkan diri ke publik dan lebih jauh lagi dapat mempengaruhi opini publik. News Menciptakan sebuah berita melalui press release, news letter, bulletin, dll. Oleh sebab itu, seorang public relations harus mampu membuat tulisan yang baik dan bernilai berita agar dapat dipublikasikan seluas - luasnya. ${ }^{4}$

Tujuan penelitian ini adalah untuk mengetahui strategi humas PT HAJJATAN.COM dalam membangun citra perusahaan e-commerce.

\section{Metode}

Penelitian ini merupakan penelitian deskriptif dengan pendekatan kualitatif. Penelitian deskriptif yaitu penelitian yang bertujuan membuat deskripsi secara sistematis, faktual, dan akurat tentang faktafakta serta sifat tertentu. Pendekatan kualitatif yang dimaksud sebagai prosedur penelitian yang menghasilkan data deskriptif berupa kata-kata tertulis atau lisan dari orang-orang dan perilaku yang dapat diamati. ${ }^{16}$

Penelitian deskriptif yang tepat cukup dari semua aktivitas, objek, proses, dan manusia. Penelitian deskriptif berkaitan dengan pengumpulan fakta dan data secara valid untuk memberikan gambaran mengenai objek yang diteliti. ${ }^{5}$

Penulis menetapkan yang menjadi bahan penelitian dalam penelitian ini adalah strategi humas dalam membangun citra perusahaan e-commerse PT Hajjatan Media solusindoyang ditujukkan kepada yang punya hajjat dan vendor penyedia jasa/barang hajatan secara online di seluruh indonesia.

Adapun yang menjadi sumber informasi (key informan) dan informan atau narasumber untuk mendapatkan berbagai informasi yang dibutuhkan dalam penelitian pada wawancara mendalam yang berlangsung diajukan pertanyaan-pertanyaan secara detail untuk mendapatkan data yang diinginkan, akurat dan sesuai dengan format penelitian.

Pada penelitian ini pengumpulan data diperoleh dari data primer dan sekunder. Data primer diperoleh melalui wawancara mendalam dengan tiga informan adalah sebagai berikut:

\begin{tabular}{cccc}
\hline No. & Nama & Jabatan & Ket. \\
\hline 1. & A & Chief Executive Officer & Key Informan \\
2. & B & Chief Operating Officer & Informan 1 \\
3. & C & Head of Marketing and PR Divison & Informan 2 \\
\hline
\end{tabular}

Lokasi penelitian dilakukan di PT HAJJATAN MEDIA SOLUSINDO JL.Kalisari Raya No. 5 cijantung, jakarta timur 13770. Waktu pelaksanaan pengambilang data dilakukan selama 4 bulan, pada bulan juni 2018 sampai september 2018. 


\section{Hasil \\ Publications \& Publicity}

Hajjatan.com memang perusahaan start up/baru dan media publikasi yang kita gunakan masih sebatas menggunakan media sosial jadi kita belum menggunakan yang namanya media seperti tv dan radio jadi fokus kita publikasi menggunakan facebook, instagram,dan melalui email marketing.

\section{Event}

Untuk event yang di buat hajjatan.com belum ada tapi ada satu event yang kita sponsori yaitu acara peduli untuk sulawesi tengah di tanggal 24 november 2018 di situ hajjatan.com berpartisipasi sebagai sponsor dan media promosi juga bagi acara peduli sulawesi tengah dalam kegiatan tersebut pasti banyak masyrakat yang melihat acara tersebut secara tidak langsung hajjatan.com akan di kenal oleh masyrakat yang melihat maupun yang menggikuti acara tersebut. ${ }^{15}$

\section{News}

Karna yang namanyai berita itu adalah bagian dari promosi nah setiap promosi hajjatan.com harus menarik dan pembahasannya harus mvengenai produk kita atau kotagori-katagori yang kita tawarkan berita itu kita akan buat semenarik mungkin sehingga masyrakat/pubik dapat tertarik untuk membacanya seperti infomasi yang kita buat dengan memadukan antara design, tuliasn dan tentunya maskot kita si mr hajjjatan lalu di publish di sosial media kami agar masyrakat tau apa itu hajjatan.com.

\section{Community Involvment}

Cara yang dilakukan hajjatan.com sekarag itu ada 2 cara yaiu kita mendatangi ketoko-toko maupun ke kategori yang masuk dalam bidang hajjatan.com dan kedua biasanya hajjatan.com menjadi sponsor dalam acara di masjid yang dekat dengan kantor hajjatan.com nah dengan begitu masyrakat sekitar jadi tau hajjatan.com itu apa dan bagi masyrakat sekitar yang mempunyai usaha makanan, makeup, tenda, dan laim-lain yang sesuai dengan kategori kita jadi bisa kami bantu dalam mempromosikan usahanya.

\section{Indentity - media}

Dalam penggunaan media sebagai promosi, misalnya dalam pembuatan konten untuk iklan di fecebook maupun intgram hajjatan.com selalu mebuat konten tersebut, konten yang di pakai dalam pembuatan isi iklan biasanya devisi sosial media hajjatan.com harus mengetahui peringatan hari setiap harinya dan peringati hari-hari besar. Bukan hanya itu saja seperti qoutes dan promosi vendor yang sudah bergabung dengan hajjatan.com. setiap postingan yang di buat di pojok sebelah kiri pasti tertulis hajjatan.com dan di dalam surat juga menggunakan kop surat hajjatan.com.

\section{Lobbying and Negotiations}

Langkah awal dalam bernegosiasi kita melakukan canvasing dan langsung mengunjungi tempattempat usaha dan berbicara langsung dengan yang punya usaha menjelaskan apa itu hajjatan.com dan memperlihatkan surat perizinan berbentuk pt dan izin keminfo, dan menjeaskan fitur dan katagori yang di miliki di dalam aplikasi berbasis web hajjatan.com sehingga dapat menarik vendor maupun masyrakat yang ada di tempat pada waktu kita canvasing, dan bukan hanya itu saja tim hajjatan.com juga akan menghubungi melalui pesawat telfon calon-calon vendor. ${ }^{11}$

\section{Social Responsibility / Investment}

Yang pertama secara dampak secara ekonomi masyrakat yang mempunyai usaha kecil menengah itu berdampak dengan adanya hajjatan.com awalnya mereka hanya di ketahui di sekitaran rumah jadi 
mereka yang ikut hajjatan bisa di akses lebih luas dan bisa di lihat oleh seluruh indonesia,dan juga yang butuh bukanya hanya masrakat sekitar saja tapi mungkin di tempat lain juga membutuhkan, kalo dampak sosial hajjatan.com ingin bekerjasama dengan pktu dan rumah zakat jadi nanti secara sosial hajjatan.com ingin membantu orang-orang yang tidak mampu melalui tempat-tempat terpercaya jadi setiap transaksi kita Rp 300., rupiah akan kami salurkan kepada pktu dan rumah zakat.

\section{Pembahasan}

\section{Publications \& Publicity}

Melakukan publikasi perusahaan hajjatan.com masih menggukan media sosial seperti instagram, facebook dan email marketing. hajjatan.com belum melakukan publikasi memlalu media televisi maupun radio karna budget untuk mengiklan di tv terlalu mahal karna ini perusahaan baru saja berjalan jadi hajjatan.com lebih memfokuskan untuk melakukan publikasi melalui media online saja karna media online untuk sekarang ini sudah cukup berkembang dan untuk mendongkrak publikasi seorang PR juga merancang acara tertentu yang dalam jangka waktu, tempat, dan objek tertentu yang secara khusus untuk mempengaruhi publik. ${ }^{6}$

\section{Event}

Hajjatan.com belum pernah memuat sebuah event khusus tapi hajjatan.com pernah menjadi sponsor dalam sebuah event kepudulian antar sesasama manusia, secara tidak langsung PR hajjatan.com sudah melakukan publikasi melalui event dan hajjatan.con menjadi sebuah sponsor di dalam event tersebut dan berkat acara tersebut hajjatan.com akan di kenal oleh masyrakat baik yang melihat maupun yang ikut menyelenggarakan acara tersebut.tidak cukup itu saja hajjatan.com juga membuat subuah berita sebagai informasi yang akan dibaca dan di ketahui oleh publik. ${ }^{7}$

\section{News}

hajjatan.com dalam membuat sebuah berita/infomasi tentu berkaitan seputar apa yang dimiliki hajjatan.com seperti produk atau katagori hajjatan.com tersebut tentunya memadukan sebuah informasi dengan desgin agar menarik di baca masyrakat atau publik dengan itu si pembaca juga tidak akan bosan membaca berita/informasi yang di buat oleh hajjatan.com di dalam media sosial dan dalam masyrakat sekitar untuk menjaga hubungan baik kepada masyrakat tentunya tugas sehari-sehari seorang public relations officer mengadakan kontak sosial dan menjaga hubungan baik dengan lingkungan setempat. ${ }^{12}$

\section{Community Involvment}

Dalam menjalin hubangan baik dengan masyrakat sekitar itu sangat penting karna dukungan dari masyrakat sekitar juga sangat berpangaruh terhadap perkembangan perushaan apa lagi perusahaan hajjatan.com yang notabandnya ingin membantu para vendor untuk memasarkannya produknya dan vendor yang di butuhkan hajjatan. Pengenalan media hajjatan.com yang biasanya di gunakan dalam promosi baik melalui media sosial dan canvasing/door to door, dan ciri khas hajjatan.com dalam promosi.

\section{Indentity - media}

Hajjatan.com melalui media memperkenalkan berbagaimana macam koten mulai dari peringatan setiap harinya yang orang-orang yang tentu belum banyak tau terkecuali peringatan hari-hari besar yang pasti ada warna merah di setiap tanggalnya jadi semua orang pasti banyak tau, hajjatan.com lalu mengemas konten tersebut dengan design dan logo di sebalah kiri atas, membuat menarik sehingga orang tertarik untuk membacanaya itu tujuan sosial media dalam pembuatan konten tersebut dan dalam pembuatan surat penawaran kerjasama hajjatan.com menggunakan logo sebagi kop surat agar yang 
membaca mengatahui bahwa surat yang itu dari hajjatan.com memberikan kepada masyrakat/publik adalah aplikasi ini memberikan semua kebutuhan untuk hajjatan anda, arti hajjatan sebutulnya tidak untuk pernikahan saja tapi lebih luas lagi seperti acara khitanan, arisan, selametan, dll juga termasuk hajjatan, dan semuanya itu sudah ada di katagori di dalam jadi untuk vendor/mitra yang ingin bergabung itu salah satu kesempatan untuk memperluas jangkaun para vendor/mitra agar di kenal ke lebih luas lagi keseluruh indonesia itu merupakan sebuah peluang yang besar bagi para vendor/mitra. Mungkin sebagian masyrakat masih ada yang ragu dengan hajjatan.com karna perushaan baru dan belum ada aktivitas transaksi dan belum banyak juga vendor/mitra yang bergabung dengan hajjatan.com sehingga mereka takut hajjatan.com adalah aplikasi bodong atau penipuan. Peran sebuah PR disini juga sangat di butuhkan bagaimana vendor/mitra ataupun masyrakat tau lebih lagi tentang hajjatan.com agar mereka percaya aplikasi hajjatan.con ini dan tentu saja keterampilan melobi secara personal dan kemampuan bernegosiasi sangat di butuhkan. ${ }^{8}$

\section{Lobbying and Negotiations}

Hajjatan.com adalah perusahaan yang legal dan hajjjatan.com sudah mengantongi izin usaha yang sudah berbentuk pt dan izin keminfo. Untuk melakukan lobbying dan negosisasi hajjatan.com menggunakan strategi door to door(dari pintu ke pintu) menemui para usaha kecil yang ada di sekitaran kantor hajjatan.com. untuk menarik para vendor dan masyrakat tim hajjatan.com juga akan menjelaskan apa yang ada di dalam hajjatan.com itu pertama hajjatan.com memiliki fitur tracking sytem(laporan keuang dan pengeluaran tercatat rapi), tracking sytem (memudahkan untuk melacak barang atau jasa), hemat waktu (tidak perlu ribet untuk mencari keluar), call center 12jam (kami standby $12 \mathrm{jam}$ dalam melayani anda), dan 100\% aman (garansi keamanan bertransaksi 100\% uang kembali). Dan 12 katagori yang di miliki hajjatan.com yaitu : florist, gedung, souvenir, cake, vidio \& photography, tari-tarian, make-up, undangan, music, cathering, dekorasi, wedding \& event oraganizer. Itulah ke-12 katagori hajjatan.com. dan untuk nomer yang di hubungi oleh pesawat telfon melalui nomer telfon kantor, dan nomer-nomer tersebut kami dapat dari blog, media sosial seperti facebook dan instragram. Memiliki tanggung jawab sosial dalam aktivitas PR menunjukan bahwa hajjatan.com memiliki kepedulian terhadapat masyrakat PR hajjatan.com yang ada di lingkungan. ${ }^{10}$

\section{Social Responsibility / Investment}

Hadirnya hajjatan.com akan membawa dampak ekonomi kepada sosial karna dengan bergabungnya masyrakat dengan hajjatan.com sebagai sarana penyedia aplikasi jasa transaksi maupun promosi jadi masyrakat yang mempunyai usaha bisa terbantu dengan adanya hajjatan.com usaha mereka menjadi akan di kenal oleh seluruh indonesia bila bergabung menjadi vendor di hajjatan.com. untuk keuntungan para vendor hajjatan mendapatkan $100 \%$ hasil penjualan produknya dan pajak yang akan di bebankan kepada para costumer sebesar 5\%. Dan dimana pendapatan akan di dapat oleh hajjatan.com berasal dari pelanggan 10\%, iklan melalui media sosial kami atau dari web hajjatan.com dan jasa ekspedisi. Dan hajjatan berkerjasama juga dengan rumah zakat dan pktu untuk membantu orang-orang yang kesusahan. Dalam strategi pencils PR hajjatan.com sudah melakukan strategi yang sudah di buat oleh philip kothler namun ada beberapa strategi yang belum di lakukan oleh hajjatan.com namun wacana sudah di buah oleh PR devision hajjatan.com. ${ }^{9}$

\section{Kesimpulan}

Teori yang di gunukan peneliti menggunakan metode "PENCILS" membangun perusahaan ecommece untuk meningkatkan citra sudah beberapa yang di lakukang oleh Hajjatan.com sebagian belum di lakukan tapi sudah dalam action plan, untuk kegiatan yang sudah di lakukan oleh Hajjatan.com sudah memberikan feedback yang signifikan dari vendor yang makin meningkat dan followers 


\section{JIKOM}

Jurnal Ilmiah Komunikasi

Volume 13, No.01, Maret. 2021

facebook yang makin banyak dan aplikasi berbasis web yang sudah di perbarui dan lebih menarik.hajjatan.com menggunakan Dalam penggolan sifat transaksi hajjatan.com menggunakan sifat transaksi B2C bisnis to customer adalah bentuk jual beli produk atau jasa yang melibatkan perusahaan penjual produk atau jasa dengan konsumen menggunakan jaringan internet.

\section{References}

1. Masindo AA. Strategi Public Relations Detikcom Dalam Meningkatkan Brand Loyalty. Jakarta: Fakultas Ilmu Dakwah dan Ilmu Komunikasi Universitas Islam Negeri ...; 2018.

2. Rosady R. Manajemen Public Relations \& Media Komunikasi Konsepsi dan Aplikasi. Jakarta PT Raja Graf Persada. 2007;

3. Kotler P. Marketing Management, Analysis, Planning and Control (Manajemen Pemuaran, Analisis Perencanaan dan Pengendalian). Terjem Herujati Jaka Wasana, Ed XI, Cetakan Keempat, Jilid II, Penerbit Erlangga, Jakarta. 2005;

4. Sugiyono. Educational Research Methods; Quantitative and Qualitative Approaches and R\&D. Bandung: Alfabeta; 2016.

5. Moleong LJ. Metodologi Penelitian Kualitatif. Bandung: PT Remaja. (edisi revisi). 2012;

6. Prastowo A. Metode penelitian kualitatif dalam perspektif rancangan penelitian. Yogyakarta: Ar-ruzz media; 2011.

7. Suryabrata S. Metode Penelitian, Jakarta: PT. Raja Graf Persada, digilib unila ac id. 2003;

8. Sugiyono. Metode penelitian pendidikan:(pendekatan kuantitatif, kualitatif dan R \& D). Alfabeta; 2008.

9. Arikunto S. Prosedur Penelitian Suatu Pendekatan Praktis. Jakarta: Rineka Cipta. 2010;

10. Djam'an S, Aan K. Metodologi penelitian kualitatif. Bandung Alf. 2010;28.

11. Mulyana D. Metode Penelitian Kualitatif. Bandung: PT Remaja Rosdakarya; 2018.

12. Kennedy John E. Marketing Communication, Taktik dan Strategi. Jakarta Bhuana Ilmu Pop. 2009;

13. Yulianita N. Corporate Social Responsibility"(CSR) sebagai Aktivitas "Social Marketing Public Relations. Mediat J Komun. 2008;9(1):123-34.

14. Harrison K. Strategic public relations: A practical guide to success. Palgrave Macmillan Publishers Australia; 2011.

15. Nova F. Crisis public relations: bagaimana PR menangani krisis perusahaan. Grasindo; 2009.

16. FATIMAH, Fatimah, et al. Komunikasi Persuasif Agen Asuransi Dalam Merekrut Calon Agen (Studi Kasus Tentang Perekrutan Calon Agen Dalam Meningkatkan Penjualan Polis di Asuransi PT. AXA). Jurnal Ilmiah Komunikasi (JIKOM) STIKOM IMA, 2018, 10.02: 110-116. 